Journal of Engineering and Applied Sciences 15 (4): 1014-1020, 2020

ISSN: 1816-949X

(C) Medwell Journals, 2020

\title{
Optimization of PV/Wind Power System Case Study: Supplying Large Industry Load in Egypt
}

\author{
${ }^{1}$ Ashraf Nasr EL-Deen Mourad, ${ }^{2}$ Adel A. Elbaset and ${ }^{3}$ Hamdy A. Ziedan \\ ${ }^{1}$ Upper Egypt Electricity Production Company, Egypt \\ ${ }^{2}$ Faculty of Engineering, Minia University, Minya, Egypt \\ ${ }^{3}$ Faculty of Engineering, Assiut University, Assiut, Egypt
}

\begin{abstract}
In this study, the possibility of using a stand-alone hybrid PV/wind power system for electricity generation for large industry load, cement factory in Egypt is investigated. To increase continuity of supply electrical power to load demand. A backup connection with grid utility based on smart connection has been used. An economic feasibility study has been made for hybrid PV/wind system to power this large industry load. A case study was done at Assiut Cement Factory in Assiut city as a representative example of large industry load in Egypt. Sizing and optimization of the hybrid system components were investigated using MATLAB code and Hybrid Optimization Model for Electric Renewable (HOMER) Software. The energy cost values of the hybrid system agree reasonably with those published before.
\end{abstract}

Key words: PV/wind power system, optimization, large industry load, HOMER Software, Assiut Cement Factory, agree reasonably

\section{INTRODUCTION}

Egypt has natural resources of renewable energy such as solar and wind. Assiut Cement Factory is one of the biggest cement factories in Egypt which is located in Assiut city, South Cairo by $380 \mathrm{~km}$, at latitude of 27 and longitude of 31. Hybrid PV/wind system is built in a remote area in the desert near to the factory as clear in (Abdel-Salam et al., 2011, Kamel and Dahl, 2005).

In this research, a feasibility analysis of stand-alone hybrid PV/wind and hybrid PV/wind/grid power systems supply large industry load, Assiut Cement Factory in Egypt is presented. The simulation was done using MATLAB code and Hybrid Optimization Model for Electric Renewable (HOMER) Software developed by National Renewable Energy Laboratory (NREL) (Ahmed et al., 2010; Eltamaly and Al-Shamma'a, 2016; Muralikrishna and Lakshminarayana, 2008 and Swarnkar et al., 2016). It allows comparing a number of different design options, taking into account the technical and economic features of system components and providing a method to find the lowest cost system design on the basis of energy source data and system components. To achieve an optimal system configuration for the case under study, thousands cases are carried out and compared with regards to the total Net Present Cost (NPC) and the Cost of Energy (COE) (Dalton et al., 2008, 2009; Nandi and Ghosh, 2010).

The size and cost of a photovoltaic system are strongly depend upon the energy requirements of the loads which are required to be served. The peak demand and energy requirements must be estimated as well as possible, to avoid unnecessarily over sizing the power system and adding to cost (Demiroren and Yilmaz, 2010). This is especially, apparent when the relative component costs are compared in the capital cost estimate for the life-cycle cost computation. It is seen in such a comparison that the unit cost of array capacity is typically appreciably higher than, for any other part of the power system (Demiroren and Yilmaz, 2010; Dalton et al., 2009; Wang and Nehrir, 2008)

It is the researchers view that the results from this research will encourage the government electricity sector to increase these projects in Egypt (Haidar et al., 2011; Nehrir et al., 2011).

\section{MATERIALS AND METHODS}

\section{Method of analysis}

Power demand and load profile assessment: The power demand is related to load estimation including cement mills, motors and transformers of the factory. This is achieved by listing the power demand of all loads, number of hours usage per day and operating voltage. From the load current in ampere-hours and the given operating voltage for each load, the power demand is calculated. The operating voltage selected for a stand-alone system is usually the voltage required by the largest load. When $\mathrm{AC}$ loads dominate, the DC system voltage should be selected for compatibility with the inverter input. If DC loads have the largest power demand, the voltage accompanying the 
largest load is selected. By using the single line diagram of the factory, it is clear that how the main components of the electric system are connected including equipment and available spares.

From the factory load data, the factory is operated at its full load all day except at rush hours of Egypt, from 17:00-22:00 when load is decreased by $25 \%$. Factory load is divided into two production lines, first and second lines. Table 1 shows the total power demand of first, second production lines and total load demand of the factory.

This section should describe and reference the techniques applied in the investigation and make clear the protocol of the study. The model and sensitivity of monitoring equipment should be stated in this section. Statistical tests should be described briefly.

Figure 1 shows the total load demand of the factory which is 158.1063 MW (201.0615 MVA and 167.3807 MVAR) all the day except at rush hours is $118.58 \mathrm{MW}$. So, the daily energy demand is:

\section{Table 1: Total power demand of the system}

\begin{tabular}{lrrr}
\hline Line & \multicolumn{1}{c}{ MVA } & \multicolumn{1}{c}{ MW } & MVAR \\
\hline Line-1 & 74.6215 & 62.7300 & 93.4896 \\
Line-2 & 126.4400 & 95.6863 & 73.8911 \\
Total load & 201.0615 & 158.1063 & 167.3807 \\
\hline
\end{tabular}

$$
\begin{aligned}
& \mathrm{E}_{\text {demand }}=158.1063 \times 19 \mathrm{H}+118.58 \times 5 \mathrm{H}(\text { rush hours }) \\
& =3596.92 \mathrm{MWh}
\end{aligned}
$$

Solar/wind resource: Monthly averaged insolation incident values on a horizontal surface $\left(\mathrm{kwh} / \mathrm{m}^{2} /\right.$ day) and monthly average wind speed $\left(\mathrm{m} \mathrm{sec}^{-1}\right)$ measured at $50 \mathrm{~m}$ high for Assiut city in Egypt (latitude of 27 and longitude of 31) is presented in Fig. 2 and 3 which are taken from NASA surface meteorology and solar energy website (NASA surface meteorology and solar energy website). Scaled annual average values of insolation level and wind speed are $5.92 \mathrm{kWh} / \mathrm{m}^{2} /$ day and $5.13 \mathrm{~m} \mathrm{sec}^{-1}$, respectively. Hybrid PV/wind system will be built in a remote area in the desert near to the factory, this area is owned by the factory, so, the land cost is not considered as factory specialized this area for the system (Eltamaly and Mohamed, 2014; Nema et al., 2009).

Economic entries: HOMER also requires some economic inputs such as the annual real interest rate which is 6\% in 2018 (Yeh and Wang, 2008; Nandi and Ghosh, 2010) and the project lifetime which is 25 years. The annual real interest rate is the nominal interest rate minus the inflation rate (Demiroren and Yilmaz, 2010; Habib et al., 1999).

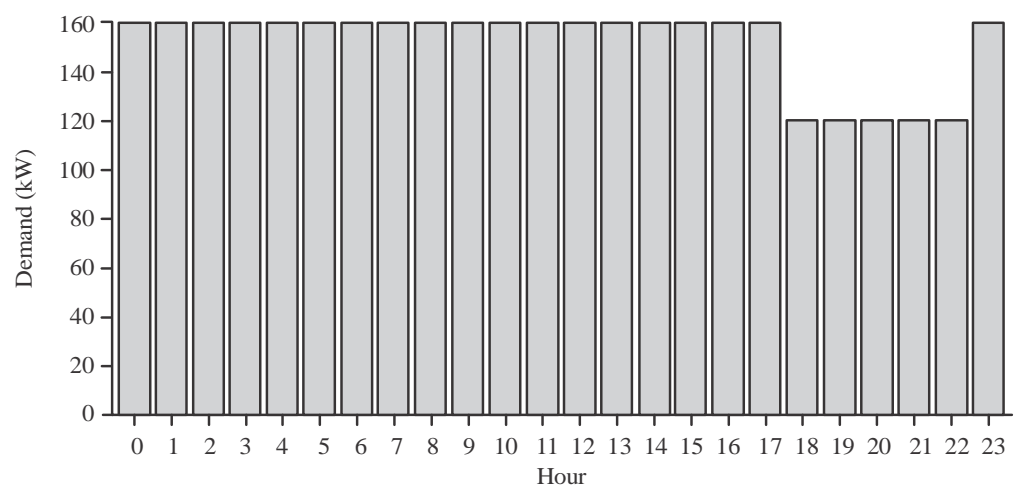

Fig. 1: Hourly load profile of total load of Assiut Cement Factory, Egypt

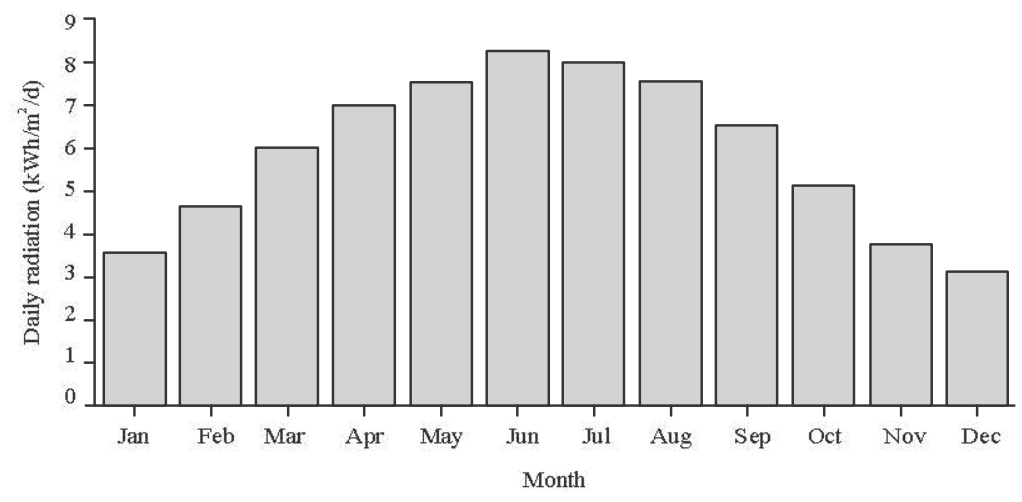

Fig. 2: Solar insolation level at Assiut Cement Factory location in Egypt (Lat. 27 and Lon. 31) 


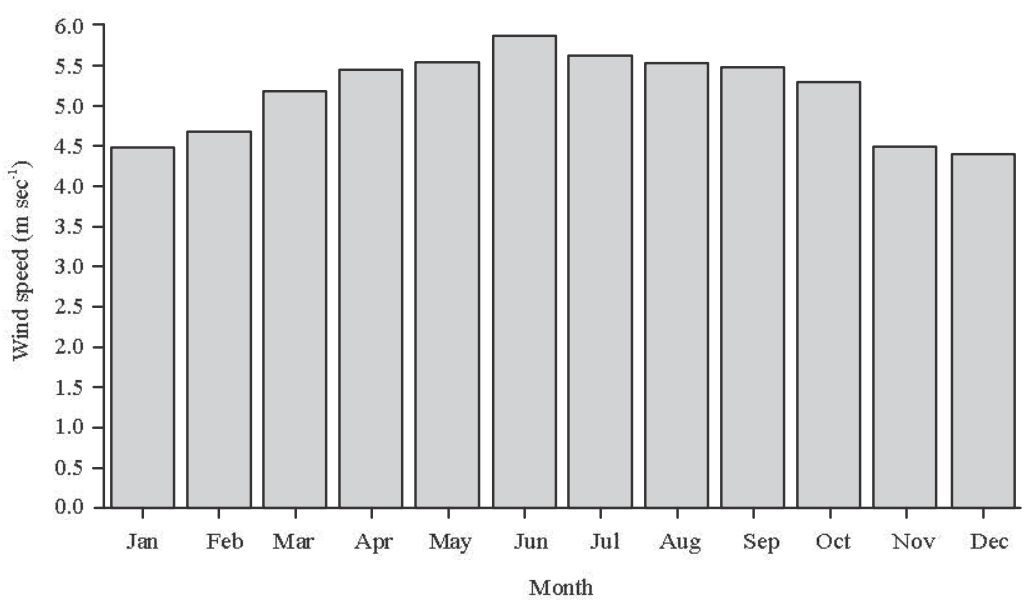

Fig. 3: Monthly wind speeds at Assiut Cement Factory location, Egypt (Lat. 27 and Lon. 31)

Constraints: Constraints are restrictions imposed by users representing conditions that the system must satisfy to be feasible. Zero annual capacity shortage is set for the industry to operate smoothly. The operating reserve is set to be $10 \%$ of the hourly load, $25 \%$ of the solar power output and $50 \%$ of the wind energy output (Jose and Rodolfo, 2009; Diaf et al., 2008; Kellogg et al., 1998; Yang et al., 2007; Yeh and Wang, 2008).

\section{RESULTS AND DISCUSSION}

\section{Economic feasibility study}

Sizing and optimization of hybrid stand-alone $\mathrm{PV} /$ wind/batteries system posed hybrid PV/wind systems: The goal of sizing the hybrid system is to meet the estimated load at minimum cost. This requires first assessing the climate conditions which determine the temporal variation of the wind speed and solar insolation in Assiut city area. These conditions are obtained from NASA as reported in Fig. 2 and 3 (Givler and Lilienthal, 2005). MATLAB code is prepared in order to calculate the total cost of the hybrid system for different combinations of wind turbines, PV panels, storage batteries inverter and converter which ensure reliable load supply without interruption irrespective of the wind speed or solar insolation. As a check of the prepared program, the sizing of the hybrid system is determined using the well-known HOMER "Hybrid Optimization Model for Electric Renewable" package.

Proposed hybrid PV/wind systems: Two proposed hybrid renewable energy systems in this study are investigated. First, the proposed system is a stand-alone hybrid PV/wind/batteries system which consists of a PV system, a wind energy conversion system, a converter and

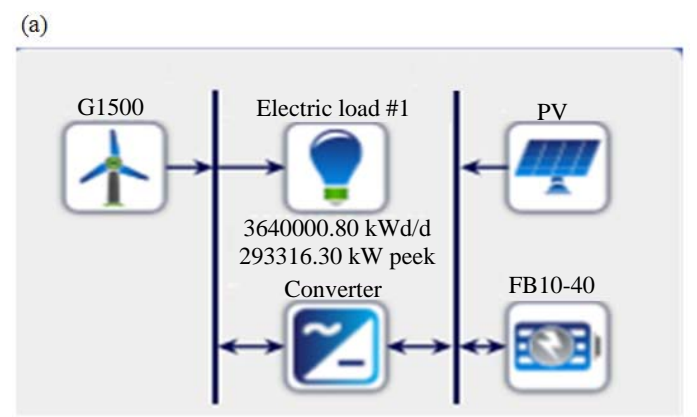

(b)

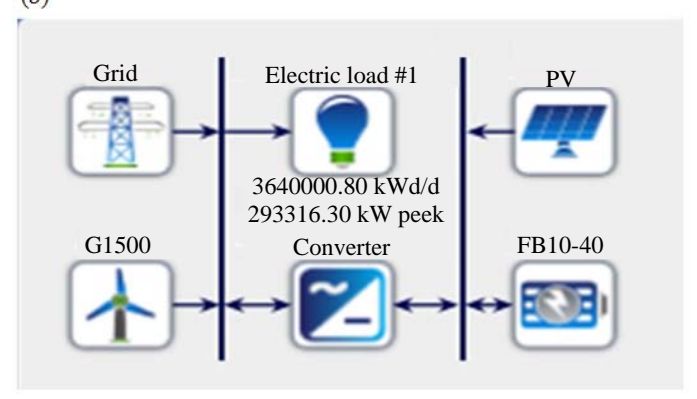

Fig. 4: Block diagram of first and second proposed hybrid systems configurations A, B; (a) First proposed hybrid system and (b) Second proposed hybrid system

batteries which is illustrated in Fig. 4a. The proposed wind turbines produce Alternating Current (AC) which serves the load directly, thus, prevents unnecessary losses. PV modules and batteries are connected to the DC bus and the DC should be converted to AC before it serves the load, Fig. 4a. The second proposed system is a grid connection hybrid PV/wind system which is used a backup of connection with grid utility based on smart connection, Fig. 4b. Grid utility 


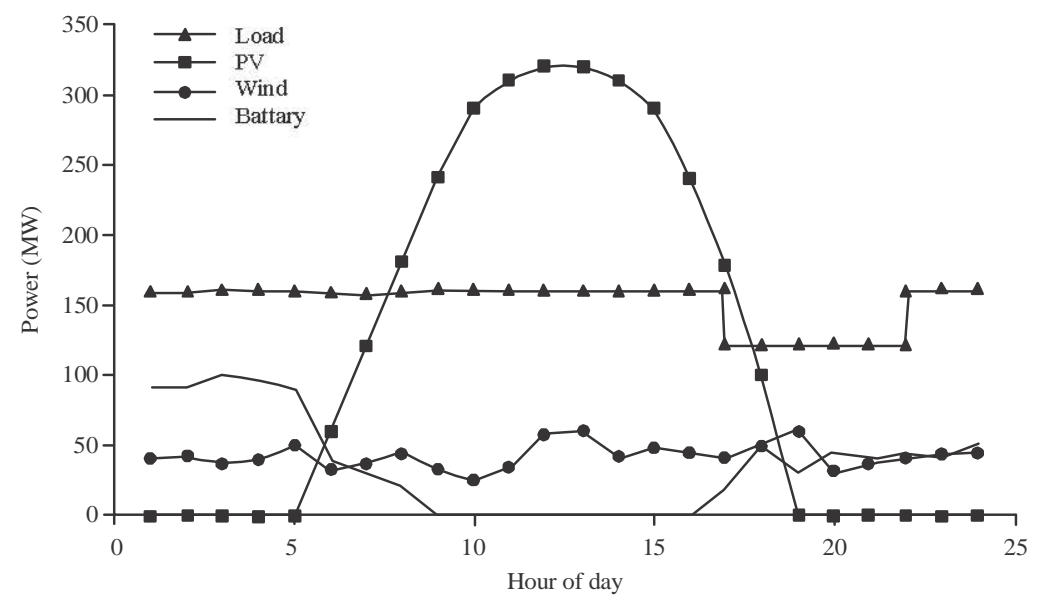

Fig. 5: Hourly power output under optimal hybrid first energy system

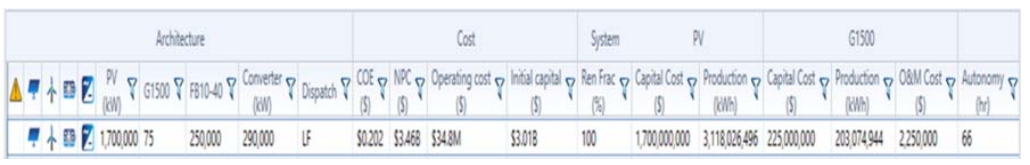

Fig. 6: Optimization result of first proposed hybrid system

connection is used to the increase continuity of supply electrical power to load and decrease the total cost of the system, Fig. $4 b$.

The output power of PV module is calculated based on the input solar radiation and taking the temperature effect into account (temporal daily variation of temperature varies in the range $20-40^{\circ} \mathrm{C}$ ). The wind turbine output is also calculated hourly based on the wind speed, air density and turbine specifications. The total generated energy is then calculated for each combination of renewable generators. The number of PV units required for supplying the load and related size of related sizes of PV, converter and batteries are determined. Total cost is calculated including capital, replacement and operation and maintenance cost during the life cycle (in years) for each component. Figure 5 shows the output results obtained by MATLAB code.

The optimization results of the first hybrid system as obtained by HOMER package corresponding to the total minimum cost are shown in Fig. 6.

A generic $1.5 \mathrm{MW}$ wind turbine is chosen with the Investment Cost (IC) of $\$ 3,000,000$ (Yang et al., 2007) and $1 \%$ annual Operational and Maintenance $(\mathrm{O} / \mathrm{M})$ cost. About 25 years are the expected lifetime of the turbines which hub height is $95 \mathrm{~m}$.

A generic flat plate PV system with a lifetime, a derating factor and a ground reflectance of respectively, 25 years, 80 and $20 \%$ was selected. No tracking system will be used with PV arrays (Diaf et al., 2008). The batteries are CELLCUBE® FB 10-40 with nominal voltage, nominal capacity and lifetime throughput of $48 \mathrm{~V}, 833 \mathrm{Ah}$ and $876000 \mathrm{kWh}$, respectively with capital cost per unit of $\$ 4000$. The converter has the efficiency of $90 \%$ and is expected to last 15 years and capital converter and battery bank is determined. By increasing the number of wind generator units for each new combination, the cost per unit is $\$ 300$.

Total energy production per year for PV and wind turbine is $3,118,026,496(94 \%)$ and $203,074,944(6 \%)$ $\mathrm{kWh} \mathrm{yr}^{-1}$ respectively as shown in Fig. 7. Figure 8 shows the cost summary of the proposed system with net total cost of $\$ 3,461,264,640$ and levelized cost of energy of $0.202 \$ \mathrm{kWh}^{-1}$. The cost of energy is comparable to that reposted in previous studies (Fernando et al., 2018; Hocaoglu et al., 2009; Mohamed et al., 2015; Khan et al., 2017).

Sizing and optimization of hybrid PV/wind/grid system: Generic $1.5 \mathrm{MW}$ wind turbine and a generic flat plate PV system with a lifetime of 25 years are used in sizing this system. Also, the same converter which has efficiency of $90 \%$ and is expected to 15 years is used too. Hybrid PV/wind system feeds the factory by $75 \%$ of its total energy demand and utility grid feeds the load by $25 \%$ as shown in Fig. 9. The optimization results of second hybrid system as obtained by HOMER package corresponding to the total minimum cost is shown in Fig. 10. Figure 11 shows cost summary of all components used in the second hybrid system with total cost of $\$ 1,830,547,760$ and levelized cost of energy of $0.08 \$ \mathrm{kWh}^{-1}$. 


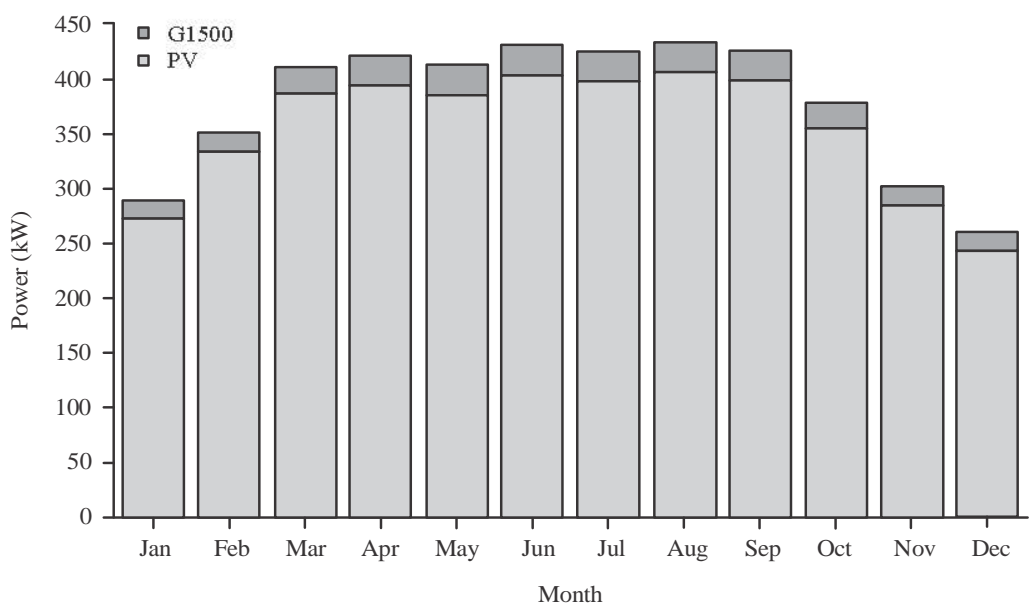

Fig. 7: Energy productions of PV and wind turbine of first proposed hybrid system

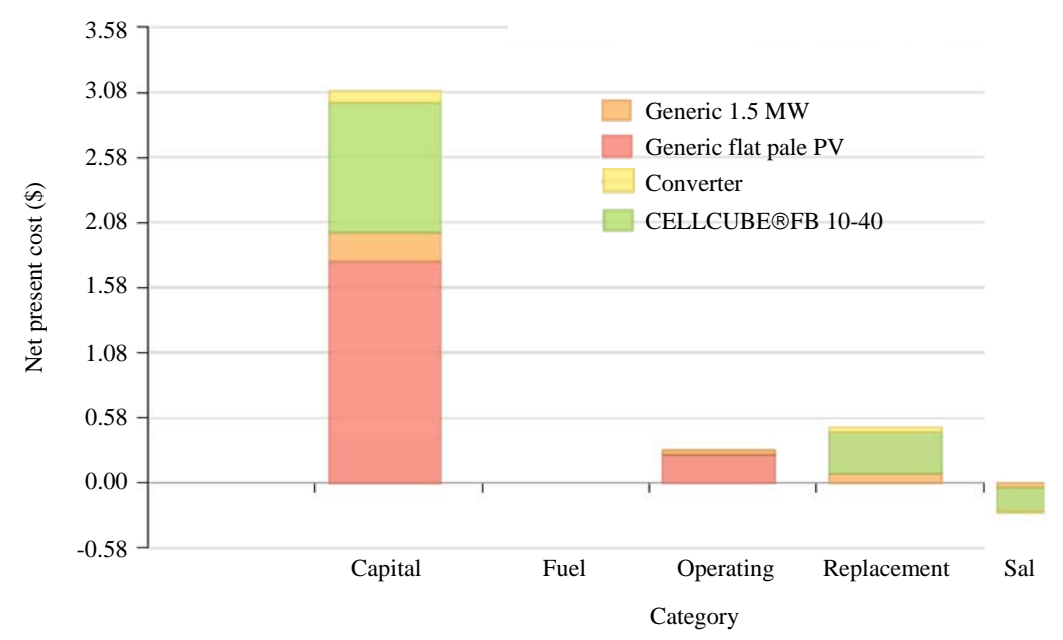

Fig. 8: Cost summary of first proposed hybrid PV/wind/batteries system

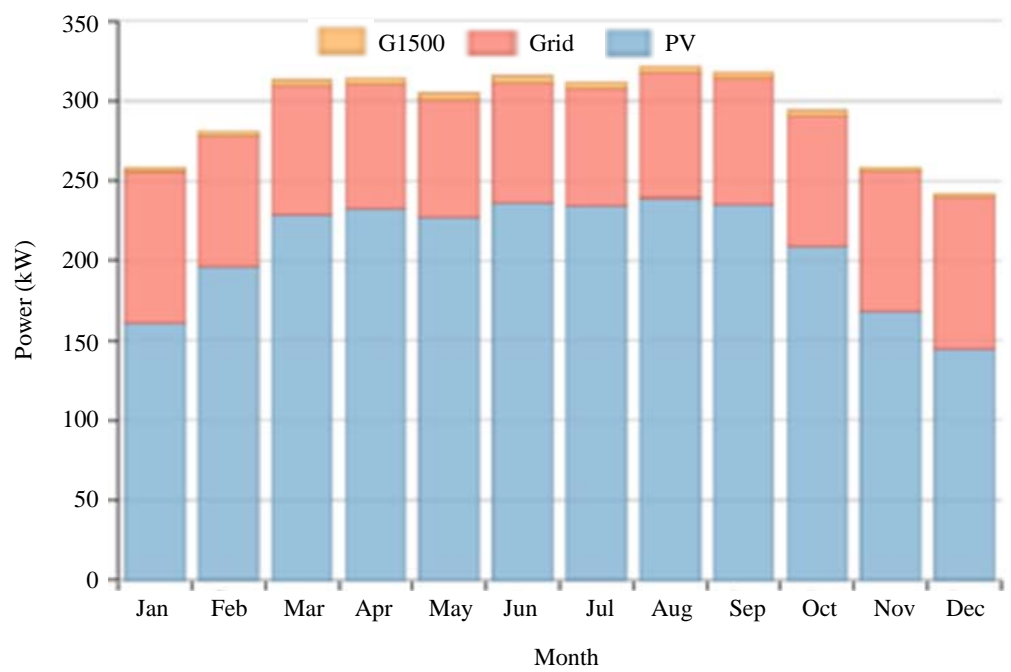

Fig. 9: Energy productions of PV/wind/grid of second proposed hybrid system 


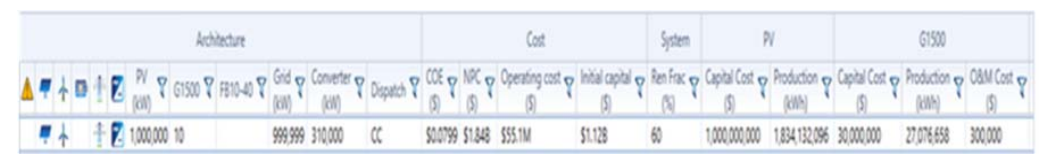

Fig. 10: Optimization result of second proposed hybrid system

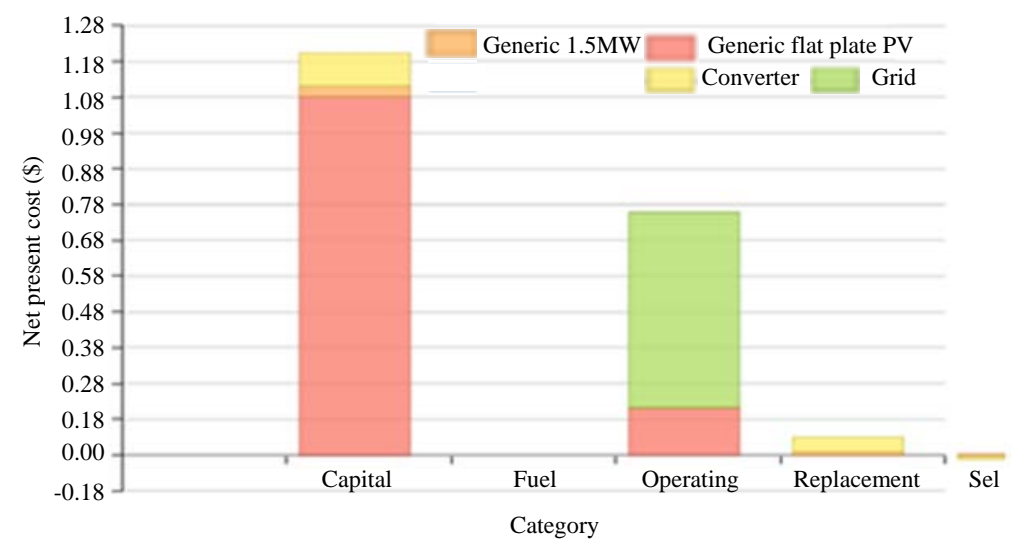

Fig. 11: Cost summary of second proposed hybrid PV/wind/grid system

\section{CONCLUSION}

The objective of this study is to design a general program for sizing and optimization of hybrid PV/wind systems feed large industry load. Assiut Cement Factory in Egypt was taken as a case study. Two hybrid systems were investigated to energize the industry load; the first system is a stand-alone hybrid $\mathrm{PV} /$ wind/battery system; total cost is $\$ 3,461,264,640$ and cost of energy is $0.202 \$ \mathrm{kWh}^{-1}$.

The second system is a hybrid grid connection $\mathrm{PV} /$ wind system which is connected with utility grid with smart connection. Total cost is $\$ 1,830,547,760$ and cost of energy is $0.08 \$ \mathrm{kWh}^{-1}$.

Sizing of hybrid PV/wind systems component are investigated with the aid of MATLAB code which agreed satisfactory with that obtained using the well-known HOMMER package.

\section{REFERENCES}

Abdel-Salam, M., A. Ahmed, H. Ziedan, K. Sayed, M. Amery and M. Swify, 2011. A solar-wind hybrid power system for irrigation in Toshka area. Proceedings of the 2011 IEEE Jordan Conference on Applied Electrical Engineering and Computing Technologies (AEECT'11), December 6-8, 2011, IEEE, Amman, Jordan, pp: 1-6.

Ahmed, S., H. Othman and S. Anis, 2010. Optimal sizing of a hybrid system of renewable energy for a reliable load supply without interruption. Eur. J. Sci. Res., 45: 620-629.
Dalton, G.J., D.A. Lockington and T.E. Baldock, 2009. Feasibility analysis of renewable energy supply options for a grid-connected large hotel. Renewable Energy, 34: 955-964.

Dalton, G.J., D.A. Lockington and T.E. Baldock, 2008. Feasibility analysis of stand-alone renewable energy supply options for a large hote. Renewable Energy, 33: $1475-1490$.

Demiroren, A. and U. Yilmaz, 2010. Analysis of change in electric energy cost with using renewable energy sources in Gokceada, Turkey: An island example. Renewable Sustainable Energy Rev., 14: 323-333.

Diaf, S., G. Notton, M. Belhamel, M. Haddadi and A. Louche, 2008. Design and techno-economical optimization for hybrid PV-wind system under various meteorological conditions. Appl. Energy, 85: 968-987.

Eltamaly, A.M. and A.A. Al-Shamma'a, 2016. Optimal configuration for isolated hybrid renewable energy systems. J. Renewable Sustainable Energy, Vol. 8, No. 4. $10.1063 / 1.4960407$

Eltamaly, A.M. and M.A. Mohamed, 2014. A novel design and optimization software for autonomous PV/wind/battery hybrid power systems. Math. Prob. Eng., Vol. 2014, 10.1155/2014/637174

Fernando, W., N. Gupta, H.H. Linn and C.S. Ozveren, 2018. Design of optimum configuration of a hybrid power system for Abertay University campus. Proceedings of the 2018 IEEE International Conference on Russian Young Researchers in Electrical and Electronic Engineering (EIConRus'18), January 29-February 1, 2008, IEEE, Moscow, Russia, pp: 1795-1800. 
Givler, T. and P. Lilienthal, 2005. Using HOMER® software, NREL's Micropower Optimization model, to explore the role of gen-sets in small solar power systems. National Renewable Energy Laboratory, Golden, Colorado, USA.

Habib, M.A., S.A.M. Said, M.A. El-Hadidy and I. Al-Zaharna, 1999. Optimization procedure of a hybrid photovoltaic wind energy system. Energy, 24: 919-929.

Haidar, A.M.A., P.N. John and M. Shawal, 2011. Optimal configuration assessment of renewable energy in Malaysia. Renewable Energy, 36: 881-888.

Hocaoglu, F.O., O.N. Gerek and M. Kurban, 2009. A novel hybrid (wind-photovoltaic) system sizing procedure. Sol. Energy, 83: 2019-2028.

Jose, L.B.A. and D.L. Rodolfo, 2009. Simulation and optimization of stand-alone hybrid renewable energy systems. Renew. Sustain. Energy Rev., 13: 2111-2118.

Kamel, S. and C. Dahl, 2005. The economics of hybrid power systems for sustainable desert agriculture in Egypt. Energy, 30: 1271-1281.

Kellogg, W.D., M.H. Nehrir, G. Venkataramanan and V. Gerez, 1998. Generation unit sizing and cost analysis for stand alone wind photovoltaic and hybrid WIND/PV systems. IEEE Trans. Energy Conversion, 13: $70-75$.

Khan, K.S., Z. Ullah, B. Khan, I. Sami, S.M. Ali and C.A. Mehmood, 2017. Assessment of hybrid off-grid wind photovoltaic system: A case study of university campus. Proceedings of the 2017 International Conference on Energy Conservation and Efficiency (ICECE'17), November 22-23, 2017 , IEEE, Lahore, Pakistan, pp: 16-21.

Mohamed, M.A., A.M. Eltamaly and A.I. Alolah, 2015. Sizing and techno-economic analysis of stand-alone hybrid photovoltaic/wind/diesel/battery power generation systems. J. Renewable Sustainable Energy, Vol. 7, No. 6. 10.1063/1.4938154.
Muralikrishna, M. and V. Lakshminarayana, 2008. Hybrid (solar and wind) energy systems for rural electrification. ARPN. J. Eng. Applied Sci., 3: $50-58$.

Nandi, S.K. and H.R. Ghosh, 2010. Prospect of wind-PV-battery hybrid power system as an alternative to grid extension in Bangladesh. Energy, 35: 3040-3047.

Nehrir, M.H., C. Wang, K. Strunz, H. Aki and R. Ramakumar et al., 2011. A review of hybrid renewable/alternative energy systems for electric power generation: Configurations, control and applications. IEEE Trans. Sustainable Energy, 2: 392-403.

Nema, P., R.K. Nema and S. Rangnekar, 2009. A current and future state of art development of hybrid energy system using wind and PV-solar: A review. Renewable Sustainable Energy Rev., 13: 2096-2103.

Swarnkar, N.M., L. Gidwani and R. Sharma, 2016. An application of HOMER Pro in optimization of hybrid energy system for electrification of technical institute. Proceedings of the 2016 International Conference on Energy Efficient Technologies for Sustainability (ICEETS'16), April 7-8, 2016, IEEE, Nagercoil, India, pp: 56-61.

Wang, C. and M.H. Nehrir, 2008. Power management of a stand-alone wind/photovoltaic-fuel cell energy system. IEEE. Trans. Energy Convers., 23: 957-967.

Yang, H., L. Lu and W. Zhu, 2007. A novel optimization sizing model for hybrid solar-wind power generation system. Solar Energy, 81: 76-84.

Yeh, T.H. and L. Wang, 2008. A study on generator capacity for wind turbines under various tower heights and rated wind speeds using Weibull distribution. IEEE. Trans. Energy Convers., 23: 592-602. 